\title{
GATE LENGTH IMPACT ON PLASMA OSCILLATIONS DUE TO HOMOJUNCTIONS IN InGaAs FET/HEMT STRUCTURES
}

\author{
P. Shiktorov, E. Starikov, and V. Gružinskis \\ Semiconductor Physics Institute, Center for Physical Sciences and Technology, A. Goštauto 11, LT-01108 Vilnius, Lithuania \\ E-mail: jane@pav.pfi.lt
}

Received: 15 November 2013; accepted 30 November 2013

\begin{abstract}
Theoretical investigation of the influence of gate length on the hybrid plasma frequencies caused by the presence of homojunctions is performed by means of hydrodynamic simulations. It is shown that when a homojunction approaches the gated channel region boundaries, a qualitative change of the spectrum of plasma excitations both in ungated and gated regions of the channel takes place. These changes can modify significantly the high-frequency regions of spectra of both admittance/impedance and current/voltage noise at the structure terminals.
\end{abstract}

Keywords: FET/HEMT structures, terahertz radiation, plasma waves, hybrid resonances

PACS: $72.20 . \mathrm{Ht}, 72.30 .+\mathrm{q}$

\section{Introduction}

Homojunctions (HJs) are widely used to form a conducting channel in modern micro- and nanometer diode and FET/HEMT structures. Usually HJs directly form regions of source and drain contacts for the conducting channel. It is well known that the presence of HJs changes essentially the frequency spectrum of plasma oscillations of free-carrier characteristics in the channel (admittance/impedance, current/voltage noise, etc.; see, e. g. [1]). The latter leads to appearance of additional hybrid resonances as a result of the collective effect of electrostatic reflection of carriers from $\mathrm{HJ}$ boundaries. In diode structures, such a collective effect is originated by the remote Coulomb interaction and involves all free carriers. In FET/HEMT structures, the gate suppresses the remote long-range action of Coulomb interaction in the gated region of the channel, thus destroying synchronous plasma oscillations of free carriers in the different areas of the channel [2]. Thus, the gate must influence essentially the frequencies of the hybrid plasma perturbations.

The aim of this communication is to present results of theoretical investigation of the influence of the gate on the hybrid plasma frequencies caused by the presence of homojunctions. The behaviour of the hybrid resonance is also compared with that of a 2D-plasma spectrum. We consider effects at thermal equilibrium and eventually show modifications of the spectra when sufficiently high voltage is applied between source and drain terminals.

\section{Numerical results}

Below we shall present hydrodynamic (HD) calculations of small-signal characteristics of FET/ HEMT structures based on 50-500-50 $\mathrm{nm} \mathrm{n}^{+} \mathrm{nn}^{+}$ $\mathrm{In}_{0.53} \mathrm{Ga}_{0.47}$ As channel with the width $\Delta=15 \mathrm{~nm}$. The gate of the length $L_{\mathrm{g}}$ varied from 50 to $400 \mathrm{~nm}$ is centered in the n-region at a distance $d=15 \mathrm{~nm}$ from the channel. The effective donor concentrations in $\mathrm{n}$ and $\mathrm{n}^{+}$regions are equal to $N_{\mathrm{D}}^{\text {ef }}=8 \cdot 10^{17} \mathrm{~cm}^{-3}$ and $N_{\mathrm{D}+}^{\mathrm{ef}}=4 \cdot 10^{18} \mathrm{~cm}^{-3}$, respectively. All the parameters of the transport model (velocity relaxation rate $v$, electron effective mass $m^{*}$, longitudinal diffusion coefficient $D$ ) are calculated by Monte Carlo simulation of the low-field transport in bulk $\operatorname{In}_{0.53} \mathrm{Ga}_{0.47}$ As with parameters corresponding to Ref. [3]. The detailed description of the HD model and procedures used to calculate frequency dependence of small-signal characteristics of FETs/HEMTs can be found in [4].

Figure 1 presents the current-voltage $(I-V)$ characteristics calculated for the above structure at the fixed values of $U_{\mathrm{ds}}$ assuming the room temperature operation corresponding to the momentum relaxation rate $v=3 \cdot 10^{12} \mathrm{~s}^{-1}$. In the low-voltage region of $U_{\mathrm{ds}} \leq 0.1 \mathrm{~V}$, all the curves coincide showing nearly linear drain-current growth with $U_{\mathrm{ds}}$. At higher values of $U_{\mathrm{ds}}$ the drain current tends to saturation which is the most pronounced at longer $L_{\mathrm{g}}$. Indeed, the longer is $L_{\mathrm{g}}$ the stronger is the perturbation of the electron concentration, the deeper is the depletion in the $\mathrm{n}$ region at $U_{\mathrm{ds}}>0$, and, hence, the lower value of the 


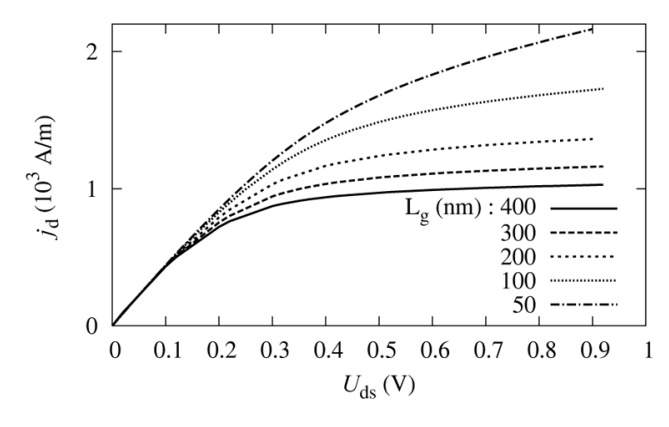

Fig. 1. Static drain-current characteristics calculated under constant voltage $U_{\mathrm{ds}}$ applied between the source and drain at decreasing values of the gate length $L_{\mathrm{g}}$ varying from 400 to $50 \mathrm{~nm}$ (from bottom to top). $T=300 \mathrm{~K}$, $U_{\mathrm{g}}=0$.

drain current is achieved approaching the $I-V$ relation saturation.

Figure 2 presents the total spectrum of the draincurrent response (the admittance real part) calculated at decreasing values of the gate length $L_{\mathrm{g}}$. It is evident that the spectrum contains two groups of peaks. The lower frequency peaks (of about 1-5 THz) correspond to $2 \mathrm{D}$ plasma oscillations, while a higher part of the spectrum (of about 15-20 THz) is due to the hybrid 3D plasma resonance. It is worthwhile to emphasize that spectra for different gate lengths differ significantly, while at the $I-V$ curve all curves coincide in the linear regime (see Fig. 1).

For 2D plasma waves, the general behaviour of the spectra for different gate lengths is similar. At zero frequency they start practically at the same value defined by the initial slope of the $I-V$ curve and then demonstrate a series of peaks. Of course, details of each series are different. The most pronounced is the series for the longest gate length. With decrease of the gate length, the number of peaks decreases and the fundamental frequency (i. e. the frequency of the first peak in the series) increases. As concerns the hybrid resonance, it is

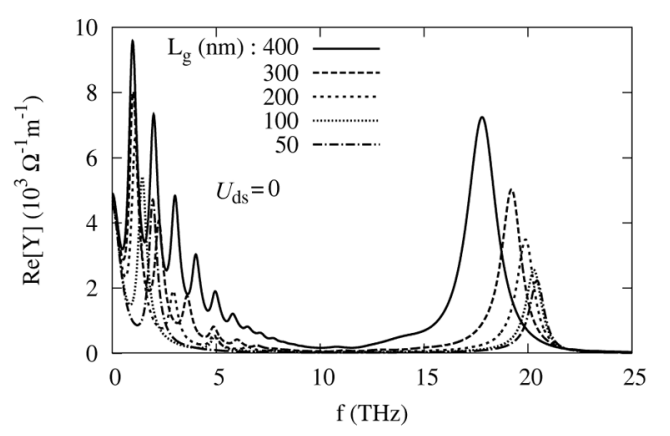

Fig. 2. Total spectra of drain-current response (admittance real part, $\operatorname{ReY}$ ) calculated by $\mathrm{HD}$ simulations at different lengths of the gated region, $U_{\mathrm{g}}=0$. evident that with increase of the gate length when gated region boundaries approach the homojunctions the hybrid plasma resonance becomes more pronounced and shifts to the lower frequency range.

It is well know that in diodes at thermal equilibrium the current response $\mathrm{ReY}$ is related with the current noise spectral density $S_{j}$ by Nyquist relation [5]:

$$
S_{\mathrm{j}}=4 k_{\mathrm{B}} T_{0} \operatorname{Re} Y .
$$

Figure 3 compares $S_{j}$ at the drain terminal calculated in accordance with Eq. (1) (solid line) and by the transfer impedance method [6]. As follows from presented results the low frequency part of the drain-current response spectrum well coincides with the noise spectrum (up to $10 \mathrm{THz}$ ). Peaks of hybrid resonances are similar but slightly differ (by about 20-25 \%) in amplitudes. Moreover, there appears an additional peak near $12 \mathrm{THz}$.

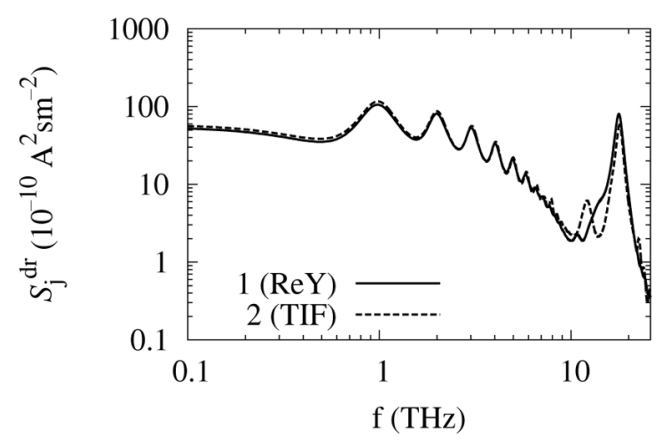

Fig. 3. Frequency dependence of the spectral density of drain-current fluctuations calculated from admittance real part $\operatorname{Re} Y$ (solid line) and by transfer impedance method (dashed line), $U_{\mathrm{g}}=0, U_{\mathrm{ds}}=0, L_{\mathrm{g}}=400 \mathrm{~nm}$.

Figure 4 shows modifications of the admittance spectrum with variations of the gate voltage. At a positive gate voltage there appear excess electrons in the channel. Qualitatively, the spectrum remains the same, of course, with improving 2D oscillations and their shift to higher frequencies due to the concentration increase. Also, there are two extra peaks in the intermediate region. At a sufficiently high negative voltage, the $n$-region becomes depleted, 2D plasma resonances disappear and apart from the hybrid resonance we see the resonance of returning curriers (see, e. g. [1] and references therein).

Figure 5 compares the total spectra of the draincurrent response calculated for the HEMT structure with $L_{\mathrm{g}}=50 \mathrm{~nm}$ under thermal equilibrium $\left(U_{\mathrm{ds}}=0\right)$ and non-equilibrium $\left(U_{\mathrm{ds}}=0.38 \mathrm{~V}\right)$ conditions. The hybrid plasma resonance remains qualitatively the 


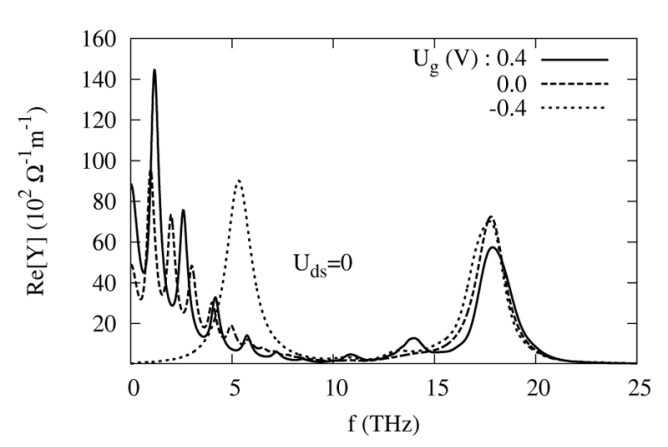

Fig. 4. Modifications of the admittance spectrum with variations of the gate voltage $U_{\mathrm{g}}, U_{\mathrm{ds}}=0, L_{\mathrm{g}}=400 \mathrm{~nm}$.

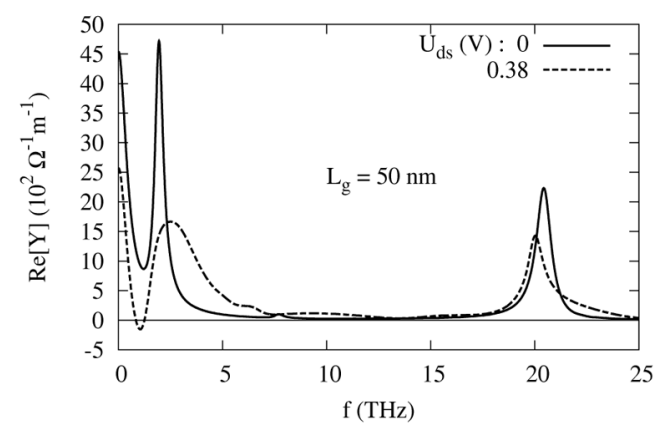

Fig. 5. Modifications of the drain-current response with increase of the drain-to-source voltage $U_{\mathrm{ds}}, U_{\mathrm{g}}=0$, $L_{\mathrm{g}}=400 \mathrm{~nm}$.

same, only a slight shift in frequency and decrease of amplitude can be observed. For 2D plasma resonance the fundamental peak broadens, decreases, and slightly shifts to higher frequencies. The most important is that the first minimum decreases and reaches negative values, leading to the development of 2D plasma instabilities (the so-called Dyakonov-Shur effect [⿰]).

Figure 6 shows the spectra of the drain-current negative admittance calculated for the HEMT with

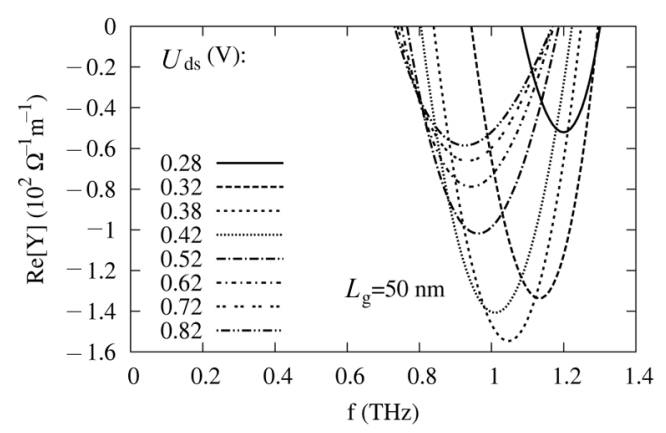

Fig. 6. Spectrum of the drain-current negative admittance with increase of $U_{\mathrm{ds}}, U_{\mathrm{g}}=0, L_{\mathrm{g}}=50 \mathrm{~nm}$.
$L_{\mathrm{g}}=50 \mathrm{~nm}$ at increasing values of drain-to-source voltage. Generally, with increase of $U_{\mathrm{ds}}$ the bell-like negative admittance appears in the high frequency region, then it grows and shifts to lower frequencies and finally decreases remaining practically in the same frequency region.

Figure 7 shows the spectra of the drain-current admittance calculated for the HEMTs with different $L_{\mathrm{g}}$ in the frequency region corresponding to the first minimum. We can conclude that the value of $L_{\mathrm{g}}$ has a crucial influence on appearance of the negative values of admittance: at long lengths of the gate the $2 \mathrm{D}$ plasma frequency $\left(f_{\mathrm{p}} \sim 1 / \sqrt{L_{\mathrm{g}}}\right)$ is too small and the momentum/velocity relaxation suppresses plasma instabilities. With decrease of $L_{g}$ the $2 \mathrm{D}$ plasma frequency grows and finally prevails the influence of the relaxation.

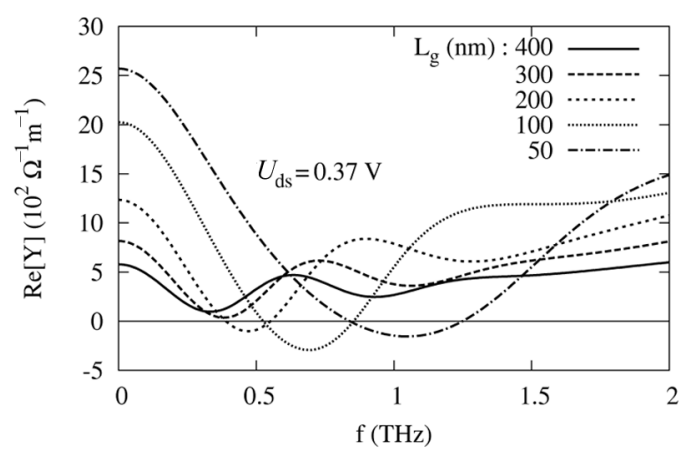

Fig. 7. Spectra of the drain-current admittance calculated for the HEMTs with different $L_{\mathrm{g}}$ in the frequency region corresponding to first minimum, $U_{\mathrm{g}}=0$.

\section{Conclusions}

Theoretical consideration of the gate impact on hybrid resonance originated by plasma oscillations at homojunctions in FET/HEMT structures was performed in the framework of the hydrodynamic modelling. Numerical results demonstrate the qualitative change of the spectrum of plasma excitations both in ungated and gated regions of the channel when the homojunction approaches the gated channel region boundaries. These changes can modify significantly the high-frequency regions of spectra of both the admittance/impedance and current/voltage noise at the structure terminals.

\section{Acknowledgements}

This work is partially supported by grant No. MIP058/2013 of the Research Council of Lithuania. 


\section{References}

[1] P. Shiktorov, E. Starikov, V. Gružinskis, L. Reggiani, L. Varani, and J.C. Vaissière, Analytical model of high-frequency noise spectrum in Schottkybarrier diodes, IEEE Electron Device Lett. 26(1), 2-4 (2005).

[2] P. Shiktorov, E. Starikov, V. Gružinskis, L. Varani, G. Sabatini, H. Marinchio, and L. Reggiani, Problems of noise modeling in the presence of total current branching in HEMTs and FETs channels, J. Stat. Mech. Theor. Exp. 01, P01047 (2009).

[3] J. Mateous, T. Gonzalez, D. Pardo, V. Hoel, H. Happy, and A. Cappy, Improved Monte Carlo algorithm for the simulation of $\delta$-doped AlInAs/ GaInAs HEMT's, IEEE Trans. Electron Devices 47(1), 250-253 (2000).
[4] E. Starikov, P. Shiktorov, and V. Gružinskis, Investigation of high-frequency small-signal characteristics of FETs/HEMTs, Semicond. Sci. Technol. 27, 045008 (2012).

[5] H. Nyquist, Thermal agitation of electric charge in conductors, Phys. Rev. 32, 110-113 (1928).

[6] P. Shiktorov, E. Starikov, V. Gružinskis, T. Gonzalez, J. Mateos, D. Pardo, L. Reggiani, L. Varani, and J.C. Vaissière, Langevin forces and generalized transfer fields for noise modeling in deep submicron devices, IEEE Trans. Electron Devices 47(10), 1992-1998 (2000).

[7] M. Dyakonov and M. Shur, Shallow water analogy for a ballistic field effect transistor: new mechanism of plasma wave generation by dc current, Phys. Rev. Lett. 71(15), 2465-2468 (1993).

\title{
UŽTŪROS ILGIO İTAKA VIENALYČIU SANDŪRŲ SUKELTIEMS PLAZMOS VIRPESIAMS InGaAs FET/HEMT DARINIUOSE
}

\author{
P. Shiktorov, E. Starikov, V. Gružinskis \\ Fiziniu ir technologojos mokslu centro Puslaidininkiu fizikos institutas, Vilnius, Lietuva
}

\section{Santrauka}

Hidrodinaminiu modeliavimu teoriškai išnagrinèta užtūros įtaka plazminių virpesių hibridiniam rezonansui FET/HEMT darinių homosandūrose. Skaitmeniniai rezultatai parode plazminio sužadinimo spektrų kokybi- nius skirtumus kanalo dalyje po užtūra ir likusiose kanalo dalyse, kai homosandūros artėja prie kanalo po užtūra kraštų. Šie pokyčiai gali stipriai pakeisti darinio admitanso / impedanso ir srovès / įtampos triukšmo spektrų aukšto dažnio sritis. 